\title{
Células con propiedades inmunoreguladoras y su impacto en la patogénesis de la sepsis
}

\author{
Mayra A. Diosa-Toro, Fabián A. Jaimes B., María T. Rugeles L. y Paula A. Velilla H.
}

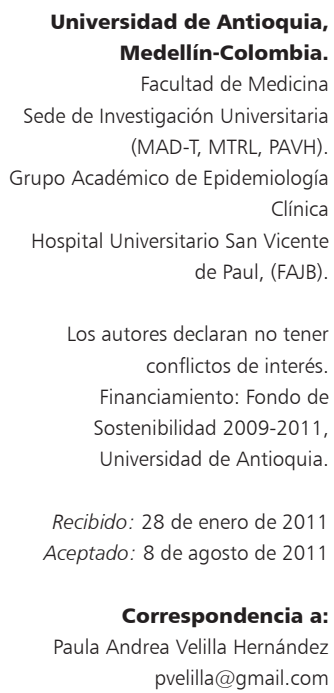

Universidad de Antioquia,

Medellín-Colombia.

Facultad de Medicina Sede de Investigación Universitaria (MAD-T, MTRL, PAVH) Grupo Académico de Epidemiología Clínica Hospital Universitario San Vicente de Paul, (FAJB).

Los autores declaran no tene conflictos de interés. Financiamiento: Fondo de Sostenibilidad 2009-2011, Universidad de Antioquia.

Recibido: 28 de enero de 2011 Aceptado: 8 de agosto de 2011

Correspondencia a: Paula Andrea Velilla Hernández pvelilla@gmail.com

\section{Introducción}

L a sepsis, una respuesta sistémica a la infección, es considerada la principal causa de muerte en las unidades de cuidado intensivo no coronarias. Sólo en Estados Unidos de América 210.000 personas mueren anualmente debido a este síndrome ${ }^{1}$ y se ha sugerido que este número es mayor en países menos desarrollados como son los de América Latina, donde aun cuando los reportes epidemiológicos podrían estar subestimando la mortalidad, se observan tasas variables que van desde 23,5\% (Colombia) hasta 56\% (Brasil) ${ }^{2}$.

La sepsis se define como un síndrome de respuesta inflamatoria sistémica con evidencia o sospecha de infección que se puede manifestar simultáneamente con algunos marcadores de enfermedad general, inflamación, anormalidad hemodinámica, disfunción orgánica o falla de perfusión tisular'. El término "sepsis" abarca un continuo de procesos fisiopatológicos heterogéneos de gravedad variable, a lo largo del cual es posible identificar diferentes estadios clínicos como lo son la sepsis grave y el shock séptico. Se habla de sepsis grave si está asociada a disfunción de órganos, hipoperfusión o hipotensión arterial, y se dice que hay un shock séptico si la hipotensión arterial persiste a pesar de la adecuada resucitación con fluidos y está acompañada de anormalidades en la perfusión ${ }^{4}$.

$\mathrm{Si}$ bien antes se pensaba que la sepsis era el resultado de una respuesta inflamatoria descontrolada, ahora es claro que la patogénesis involucra varios procesos concomitantes integrados y frecuentemente antagónicos, que implican tanto una respuesta inflamatoria exagerada como mecanismos de supresión inmune ${ }^{5}$. De acuerdo con esto, se acepta que junto con la respuesta inflamatoria destinada a eliminar el patógeno, se inician mecanismos para controlar el estado de hiperactivación inmunológica; sin embargo, aunque los eventos anti-inflamatorios son esenciales para la restauración de la homeostasis inmune, éstos pueden resultar en inmunosupresión y finalmente la muerte, debido a la incapacidad de responder a infecciones secundarias en el período post-séptico.

\section{Inmunopatogénesis de la sepsis}

\section{Proceso inflamatorio}

El consenso actual sobre la definición de la sepsis como un síndrome de respuesta sistémica producto de una infección no hace referencia al microorganismo responsable de ésta ${ }^{4}$. Sin embargo, es claro que el reconocimiento inicial del patógeno por células de la inmunidad innata está mediado por los patrones moleculares asociados a patógenos (en inglés pathogen-associated molecular patternsPAMP $)^{6}$, presentes en diferentes grupos de organismos infecciosos como bacterias, virus, hongos y protozoos y sus correspondientes receptores de reconocimiento de patrones (en inglés pattern recognition receptors-PRR), entre ellos los receptores tipo toll (en inglés toll like receptors-TLR) ${ }^{7}$. La consecuencia de la interacción inicial entre el microorganismo y el hospedero es la activación de las células 
del sistema inmune innato, entre las que se destacan los monocitos/macrófagos y las células dendríticas inmaduras, por la liberación de las citoquinas pro-inflamatorias FNT- $\alpha$ e IL-1- $\beta$ y de mediadores pro-inflamatorios secundarios como IL-6, IL-8 e IL-12 ${ }^{8}$.

Otras citoquinas solubles han sido identificadas como mediadores críticos durante el curso clínico de la sepsis. El factor inhibitorio de la migración de los macrófagos (en inglés macrophage inhibitory factor-MIF) es inducido por glucocorticoides y tiene como función regular los efectos anti-inflamatorios de éstos, promoviendo la translocación nuclear del factor de transcripción NF- $\kappa \mathrm{B}$ y de ese modo la transcripción de FNT- $\alpha$ y otras citoquinas pro-inflamatorias ${ }^{9}$. En modelos murinos de shock séptico, el bloqueo del MIF mediante anticuerpos y el estudio de ratones knockout para este gen muestran un incremento en la supervivencia después del reto endotóxico con lipopolisacárido (LPS) y la enterotoxina B de Staphylococcus aureus (SEB). De forma análoga, los pacientes sépticos que muestran niveles más elevados de MIF parecen tener peor pronóstico y mayor riesgo de muerte ${ }^{10,11}$. La proteína del grupo de alta movilidad (HMGB1) también ha sido reconocida como un mediador tardío de la sepsis. En los monocitos, HMGB1 es inducida por FNT- $\alpha$ e IL1 y a su vez, la primera potencia la expresión de los segundos por lo que actuaría como un mecanismo de retro-alimentación positiva $^{12}$. Como consecuencia de lo anterior, se da una activación prolongada de los monocitos y por ende la propagación y amplificación de respuestas pro-inflamatorias posteriores a la respuesta inflamatoria inicial.

\section{Inmunomodulación durante la sepsis}

Durante mucho tiempo se pensó que el curso clínico de la sepsis obedecía a un estado descontrolado de hiperactivación inmunológica ${ }^{13}$, por lo que las investigaciones se centraron en la búsqueda de agentes que pudieran bloquear los componentes de la cascada de inflamación, como por ejemplo antagonistas de los receptores de FNT- $\alpha$ y de IL-1- $\beta^{5}$. La falla terapéutica de los agentes antiinflamatorios para combatir la sepsis llevó a reconsiderar si realmente la muerte de estos pacientes era consecuencia de una inflamación descontrolada ${ }^{13,14}$. Ahora es claro que durante la respuesta inflamatoria del hospedero también se producen mediadores anti-inflamatorios que tienen como objetivo mantener un equilibrio entre los dos estados; en la actualidad, es evidente que los pacientes que sobreviven a la fase inicial de la sepsis exhiben características consistentes con inmunosupresión ${ }^{6}$.

Entre los términos empleados para describir los eventos anti-inflamatorios que ocurren durante la sepsis se encuentran "inmunosupresión inducida por sepsis", "inmunoparálisis" y "síndrome de repuesta anti-inflamatoria compensatorio" (en inglés Compensatory anti-inflamatory response syndrome-CARS). Estos conceptos reflejan la presencia de anergia de células T, alteración funcional de los monocitos y un incremento en el riesgo de adquirir infecciones secundarias ${ }^{15}$. Entre los mecanismos de regulación negativa de la respuesta inmune que contribuyen al estado de inmunosupresión característico de los procesos sépticos, se encuentran: la inducción de apoptosis en poblaciones de linfocitos $\mathrm{T}$, células dendríticas y neutrófilos; la alteración funcional de monocitos, evidenciada por la baja expresión de moléculas del complejo mayor de histocompatibilidad $(\mathrm{CMH})$ clase II, particularmente HLA-DR, y la baja capacidad de secretar citoquinas pro-inflamatorias como IL-1 $\beta$, IL-6 y TNF- $\alpha$; y la producción de moléculas con propiedades anti-inflamatorias como IL-4, IL-10, TGF- $\beta$, el receptor soluble de FNT, el receptor antagonista de IL-1 (IL-1ra) y el receptor sustituto de IL-1 tipo II ${ }^{15}$.

Si bien distintos mediadores solubles con propiedades anti-inflamatorias han sido descritos como moduladores en el proceso evolutivo de la sepsis y se ha definido la importancia de la apoptosis de células del sistema inmune durante el curso de la sepsis, el papel del componente celular con propiedades reguladoras ha sido poco explorado a pesar del estado de "hiperactivación" inmunológica que caracteriza a la sepsis. Dentro de ese componente celular, los principales exponentes son los linfocitos $\mathrm{T}$ CD4+CD25+ (T reguladores-Treg), las células dendríticas con propiedades inmunoreguladoras, las células asesinas naturales $(\mathrm{NK})$, los linfocitos $\mathrm{T}$ con TCR invariante restringidas por la molécula CD1d (células iNKT) y los linfocitos T gd (LTgd). El papel que estas poblaciones celulares pueden tener dentro del proceso evolutivo de la sepsis es complejo, debido a que dependiendo del fenotipo que exhiban, así como del predominio de algún subgrupo en las diferentes fases del proceso, estas células pueden actuar como pro-inflamatorias o como inmunosupresoras a través de la secreción de mediadores solubles ${ }^{8}$.

\section{Subpoblaciones celulares con propiedades reguladoras}

\section{Células T reguladoras CD4+ CD25+}

Las células Treg han sido identificadas tradicionalmente por la expresión de la molécula CD4 y la cadena $\alpha$ del receptor de IL-2 (CD25) ${ }^{16}$. Recientemente se ha definido que la baja expresión de la molécula CD127 (cadena $\alpha$ del receptor de IL-7) en conjunto con una expresión elevada de CD25 constituye una mejor caracterización de la población ${ }^{17}$. Las Treg también expresan otras moléculas de superficie como el CTLA-4 y el receptor de FNT inducido por glucocorticoides (en inglés glucocorticoid induced TNF receptor-GITR); sin embargo, no existen marcadores de superficie que distingan de forma precisa a las Treg naturales de las células T CD4+ activadas o de las células Tr1 y Th3 (células T reguladoras adaptativas). Por esto se considera que la expresión del factor de transcripción 
intracelular FoxP3 es el mejor marcador para definir la población de células Treg, cuya intensidad de expresión se asocia con su actividad supresora ${ }^{18}$.

Las células Treg pueden regular la función de linfocitos T CD4+ y CD8+, linfocitos B, células dendríticas, células NK y de monocitos/macrófagos a través de mecanismos directos que involucran el contacto células-célula, y/o a través de la secreción de factores solubles como IL-10, TGF- $\beta$. Igualmente, esta células se caracterizan por inducir la producción de la enzima indoleamina 2,3-dioxigenasa (IDO) en células presentadoras de antígeno (CPA), provocando deficiencias en la producción de triptófano y alterando de ese modo la activación eficiente de las células $\mathrm{T}$ efectoras ${ }^{19}$.

Durante un proceso infeccioso el efecto de las Treg puede ser benéfico o perjudicial, dependiendo del tipo de infección, del tiempo de activación y de la aparición oportuna de una respuesta inmune eficiente del hospedero $^{20}$. Dado el estado de inmunoparálisis que se postula en la sepsis, algunos estudios han buscado determinar la participación que podría tener la población de Treg durante la enfermedad. En una pequeña cohorte de pacientes con shock séptico en la que se demostró una disminución en la expresión del HLA-DR en los monocitos, hecho consistente con una inmunoparálisis, se observó también un incremento en el porcentaje de células T CD4+ CD25+ circulatorias después del inicio del shock. Dicho incremento fue similar hasta el día quinto entre los sobrevivientes y los que fallecieron, después del cual se observó que en estos últimos los niveles de células T CD4+ CD25+ circulatorias siguieron aumentando hasta el momento de la muerte ${ }^{21}$. Un trabajo posterior, en el que se incluyó un número mayor de pacientes, mostró que tal incremento era relativo al ser consecuencia de la pérdida selectiva de las células T CD4+ CD25- y no a la proliferación de las células T CD4+ CD25+, ya que el número absoluto de éstas permanecía constante. Lo anterior podría indicar que las Treg son menos susceptibles que otros linfocitos a la apoptosis masiva inducida durante la sepsis ${ }^{22}$. Resultados similares se obtuvieron en un estudio más reciente, en el que se encontró que el porcentaje de Treg estaba aumentado en pacientes con SIRS (en inglés systemic inflamatory response syndrome) y con sepsis, al compararse con individuos control y era más elevado en los pacientes con sepsis en quienes además se observó un aumento en los niveles plasmáticos de CD25 soluble ${ }^{23}$. Un incremento similar en el porcentaje de Treg ha sido observado en pacientes con trauma ${ }^{24}$ y en modelos murinos de sepsis abdominal, en los que además de observarse el incremento de las Treg circulatorias, se observa un aumento en el porcentaje de las células Treg esplénicas ${ }^{25,26}$.

Adicionalmente, otro estudio demostró una correlación entre el incremento de Treg y la disminución de la respuesta linfoproliferativa, tanto en células mononucleares de sangre periférica de pacientes con shock séptico, como en esplenocitos de ratón a los que se les indujo la sepsis mediante el modelo de ligación y puncion cecal (LPC). La respuesta en estos últimos se restauró después de la regulación negativa de la expresión de Foxp3 mediante la transfección ex vivo de siARN dirigido contra dicho gen ${ }^{27}$. Esto podría reflejar un papel de las Treg en el desarrollo de la anergia de linfocitos que se observa después del shock séptico ${ }^{28}$. Hasta le fecha, sin embargo, no ha sido posible establecer la relevancia clínica de estos hallazgos en los pacientes con sepsis.

\section{Células dendríticas}

Las células dendríticas (CDs) constituyen un puente clave entre la inmunidad innata y la adaptativa ya que son las principales células presentadoras de antígeno. En respuesta al reto inmunológico, son una fuente importante de citoquinas que tendrán entre sus funciones principales polarizar la respuesta de los linfocitos $\mathrm{T}$ hacia un perfil Th1, Th2, Th17 o un fenotipo regulador. Esta población celular comprende un grupo heterogéneo de células que se ha categorizado de acuerdo con la expresión de una serie de marcadores de superficie, los cuales difieren en las funciones inmunes así como en la producción de citoquinas, procesamiento y presentación de antígenos ${ }^{29}$.

El papel que desempeñan las CDs durante el curso clínico de la sepsis y su contribución a la patogénesis de la misma no ha sido determinado ${ }^{30}$. El uso de modelos animales como el de LPC murino, que simula una sepsis polimicrobiana, ha permitido determinar que hay una pérdida sistémica y local significativa de CDs en los nódulos linfoides y que tal pérdida ocurre después de la apoptosis de los linfocitos T murinos CD3+ CD4+ que se observa con frecuencia durante los síndromes sépti$\cos ^{31}$. Además, se ha mostrado que la pérdida de células dendríticas $\mathrm{CD} 11 \mathrm{c}^{\text {high }} \mathrm{CMH}-\mathrm{II}^{\text {high }}$ incrementa de forma dramática la mortalidad por sepsis inducida mediante LPC, mientras que la administración de CDs mieloides derivadas de médula ósea restaura la supervivencia en este modelo de sepsis polimicrobiana ${ }^{32}$. Otros estudios han demostrado que las CDs esplénicas de ratones sépticos maduran correctamente pero son incapaces de secretar IL-12, importante para la inducción de una inmunidad eficiente contra infecciones bacterianas; en su lugar, liberan grandes niveles de IL-10 en comparación con las CDs de los ratones control ${ }^{33}$. La razón de esta respuesta de citoquinas alterada de las CDs esplénicas durante la sepsis no es clara; sin embargo, se han caracterizado varias modificaciones de histonas, como metilaciones y acetilaciones, en regiones promotoras del gen de la IL-12 como un mecanismo regulador de la producción de la citoquina por las CDs esplénicas después de la inducción de sepsis ${ }^{34}$.

Hay pocos estudios realizados en humanos. Se ha reportado una reducción en el porcentaje de área ocu- 
pada en el bazo por las células dendríticas foliculares (CDFs) - una subpoblación de dendríticas de origen no hematopoyético- tanto en pacientes con trauma como con sepsis, siendo más notoria la reducción en los últimos; sin embargo, las poblaciones de macrófagos esplénicos permanecen constantes en ambos (pacientes con trauma y con sepsis $)^{35}$. Lo anterior sugiere que la pérdida de las células dendríticas podría constituir un evento específico, ya que no se evidencia una apoptosis generalizada de células del órgano linfoide. Otro trabajo más reciente en el que se evaluó la frecuencia de CDs en muestras de sangre periférica de pacientes con shock séptico, reveló que hay una disminución en el número de CDs circulatorias de pacientes cuando se compara con el conteo de individuos sanos; además, esta reducción fue más drástica en los pacientes que fallecieron y se correlacionó con la gravedad del shock ${ }^{36}$.

Dado que las CDs son las únicas células presentadoras de antígenos capaces de inducir respuestas inmunes primarias, la reducción en las CDs circulatorias podría explicar por qué los pacientes que sobreviven a las fases iniciales de la sepsis son susceptibles de sucumbir ante infecciones secundarias, ya que son incapaces de establecer una respuesta inmune específica contra el nuevo agente infeccioso.

\section{Células asesinas naturales (NK)}

Las células NK son una subpoblación de linfocitos caracterizada por su tamaño grande y los numerosos gránulos citoplasmáticos; fenotípicamente se definen por la expresión en la superficie de las moléculas CD16 y/o CD56, y la ausencia de la molécula CD3. Dos subpoblaciones distintas de células NK se han observado en humanos, con base en la expresión diferencial de las moléculas CD16 y CD56. Aproximadamente 90\% de las células NK en sangre periférica tienen una baja expresión de CD56 y expresan en alta densidad el receptor CD16 $\left(\mathrm{CD} 16^{\text {bright}} / \mathrm{CD} 56^{\mathrm{dim}}\right)$. Esta subpoblación es principalmente citotóxica, participa activamente en el proceso de citotoxicidad celular mediada por anticuerpos y produce poco IFN- $\gamma$. El 10\% restante de células NK son CD56 bright/ $\mathrm{CD}^{16}{ }^{\mathrm{dim}}$ o CD56 ${ }^{\text {bright}} / \mathrm{CD} 16$; ; esta subpoblación produce grandes cantidades de quimoquinas y citoquinas como el IFN- $\gamma$, expresa el receptor de alta afinidad para la IL-12, no expresan perforina y su actividad citolítica y antitumoral es reducida ${ }^{37}$. A pesar de ser la subpoblación de menor frecuencia en la sangre, la subpoblación de células NK con fenotipo $\mathrm{CD}^{6} 6^{\text {bright }}$ se encuentra en gran número en el útero de las mujeres embarazadas y en la región parafolicular de los nódulos linfoides, sugiriendo un papel regulador de esta subpoblación celular.

Modelos murinos han evidenciado que las células NK exhiben un papel perjudicial durante el curso de un cuadro de sepsis. Ratones deficientes de células NK que cursan con un proceso de sepsis son más resistentes a la muerte inducida por este síndrome, lo cual fue asociado a la atenuación de la respuesta inflamatoria ${ }^{38,39}$. De hecho, la activación de las células NK induce la secreción de citoquinas como IFN- $\gamma$ y FNT- $\alpha$, que contribuyen a la falla multisistémica y al cuadro clínico del shock séptico. Diferentes modelos de sepsis han hecho evidente que las células NK son indispensables en la activación y actividad fagocítica de los macrófagos para la eliminación de los patógenos ${ }^{40}$.

\section{Células NKT con TCR invariante restringidas por CD1d}

Un grupo muy particular de linfocitos $\mathrm{T}$ humanos que expresa algunos de los marcadores clásicamente encontrados en las células NK (CD16, CD56, CD161, NKR) han sido denominados células $T$ asesinas naturales (células NKT). Los receptores expresados por las células NKT varían según el estado de activación y la ubicación tisular $^{41}$. Dentro de las células NKT humanas existe una pequeña subpoblación de células restringidas por la molécula CD1d, que tienen un TCR invariante conformado por una cadena alfa con el rearreglo Va24Ja18, preferencialmente apareada con la cadena Vb11 ${ }^{42}$; este grupo se conoce como células con TCR invariante restringidas por CD1d o células NKT invariantes (iNKT).

Estas células son activadas por glicolípidos presentados por la molécula no polimórfica CD1d, expresada por las CDs y otras CPA; se considera que esta interacción es fundamental para las funciones inmunomoduladoras de las células iNKT ${ }^{43}$ Las iNKT cumplen un papel crítico en la vigilancia antitumoral ${ }^{44}$, en el control de las reacciones autoinmunes mediadas por linfocitos $\mathrm{T}^{45} \mathrm{y}$ en la respuesta contra diferentes patógenos intracelulares ${ }^{46}$.

Las células iNKT han sido divididas en tres subgrupos según la expresión de CD4 y CD8: las células iNKT CD4+ producen principalmente citoquinas del patrón Th2 como IL-4 e IL-10. De otro lado, las células iNKT CD8+ y las doblemente negativas (DN) producen principalmente citoquinas del patrón Th1 como el IFN- $\gamma$ y el FNT- $\alpha$; además, secretan perforina en respuesta a la estimulación con IL-2 e IL-12. Esto indica que la actividad inmuno-reguladora de las células iNKT puede ser el resultado de la activación selectiva de alguno de los subgrupos ${ }^{47}$. Al igual que otras poblaciones celulares con función inmuno-reguladora, las células iNKT afectan tanto a los LT efectores como a las CPA, en particular a las CDs, a las que les puede inducir una función tolerogénica ${ }^{48}$.

El papel de esta población celular en los procesos sépticos no está claramente definido, aunque se ha sugerido que estas células son importantes en la activación de macrófagos y CDs a través de la producción de IFN- $\gamma$. Ratones deficientes de células iNKT son resistentes a la muerte inducida por LPS o ADN bacteriano, lo cual fue asociado a los bajos niveles plasmáticos de IFN- $\gamma$ 
y FNT- $\alpha^{49,50}$. Adicionalmente, se ha observado que la deficiencia de esta población celular está asociada con la restauración de la frecuencia de diferentes poblaciones celulares como células T CD4+ y CD8+ y CDs en el bazo, así como con una disminución de Fas y granzima $\mathrm{B}$ en células T esplénicas y hepáticas ${ }^{51}$. De otro lado, en el modelo de sepsis de LPC se observó que ratones tratados con un anticuerpo bloqueador anti-CD1d exhiben mayor supervivencia, lo cual fue asociado a la disminución en la producción de IL-10 e IL-6, citoquinas clásicamente involucradas en los procesos sépticos ${ }^{52}$. Así mismo, aunque no se ha descrito para modelos de sepsis, en un modelo de lesión por quemadura se observó un aumento en la producción de IL-4 por células iNKT activadas, lo cual se correlacionó con la supresión de la respuesta inmune asociada a etapas tempranas de este proceso ${ }^{53}$. De esta manera, se podría concluir que esta población celular podría tener un papel dual durante los procesos sépticos, al ser fuente importante de citoquinas proinflamatorias como IFN- $\gamma$ pero también al ser la fuente principal de citoquinas anti-inflamatorias como la IL-4 e IL-10, exacerbando de esta manera diversos mecanismos de respuesta inmune en la sepsis.

\section{Linfocitos T gamma/delta $(\gamma \delta)$}

Los LTgd comprenden una subpoblación de células $\mathrm{T}$ considerada tanto del sistema inmune innato como del adaptativo, debido a la variedad de subgrupos que se pueden encontrar. Su actividad se desarrolla principalmente en la etapa temprana de las infecciones, mediando reacciones desencadenas por antígenos presentados en el contexto de moléculas no clásicas del CMH, principalmente el CD1c. A diferencia de los LTab, la mayoría de los LTgd carecen de la expresión de las moléculas CD4 y CD8, la diversidad de su TCR es limitada y están localizadas principalmente en los tejidos epiteliales. En sangre periférica se puede observar dos subpoblaciones de LT gd basados en la composición del TCR; el subgrupo predominante (70\%) expresa la cadena $\mathrm{Vd} 2$ asociada a la cadena $\mathrm{Vg} 9$, mientras que un subgrupo menor expresa la cadena $\mathrm{Vd}^{54}$.

Estas células pueden producir tanto citoquinas del perfil Th1 como del Th2, modulando de esta manera la diferenciación funcional de la respuesta de linfocitos $\mathrm{T}$ $\mathrm{ab}^{55}$. Los LTgd exhiben capacidad inmuno-reguladora, participando en la regulación de la respuesta inflamatoria mediada por los LTab, evitando una respuesta inmune excesiva que pueda ocasionar daño tisular. Varios subgrupos de LTgd han mostrado esa actividad reguladora, incluyendo en los humanos a las células $\mathrm{Vg} 1+$ periféricas $^{56}$. Los ratones deficientes de esas subpoblaciones celulares exhiben un proceso inmunopatológico grave después de la infección con diferentes patógenos como Listeria monocytogenes, Mycobacterium tuberculosis y Klebsiella $\mathrm{spp}^{57}$. En humanos, la deficiencia de LTgd intra-epiteliales se asocia con la enfermedad inflamatoria del intestino ${ }^{58}$.

Al igual que para otras células con función inmunoreguladora, los mecanismos por los cuales los LTgd ejercen su función es incierta. Se ha postulado que esa función reguladora puede estar asociada con la expresión elevada de la timosina $\beta 4$ oxidada linfoide, la cual es un potente agente anti-inflamatorio; la producción de TGF- $\beta$; la expresión de Fas-L, granzimas A y B, y linfotoxina, fenómenos consistentes con su capacidad de mediar la apoptosis de células cuya función necesita ser controlada ${ }^{59}$.

La evidencia que existe sobre el papel que exhiben los LTgd durante el desarrollo de la sepsis es contradictoria. Ratones deficientes de esta población celular son más susceptibles a desarrollar sepsis, lo que se ha asociado con una disminución plasmática de citocinas pro-inflamatorias como IFN- $\gamma$ y FNT- $\alpha$, así como al establecimiento de un estado de imununosupresión que contribuye a la mortalidad de estos ratones ${ }^{60,61}$. En contraste, en otros estudios no se ha observado un efecto en la supervivencia o producción de citoquinas en ratones deficientes de LTgd que cursan con un proceso de sepsis (LPC) ${ }^{38}$, mientras que en otros se sugiere que la deficiencia de LTgd disminuye la morbilidad de ratones que cursan con infecciones bacterianas $^{62}$. Adicionalmente, algunas alteraciones en la función y en el porcentaje de esta población celular se han observado en pacientes con shock séptico y trauma ${ }^{63,64}$.

\section{Conclusión}

La inmunopatogénesis de la sepsis comprende una serie de cambios celulares, humorales y fisiológicos de la respuesta inmune que el hospedero monta frente al patógeno responsable de la infección. Si bien hace unos años se definía como un estado de hiperactivación inmunológica, ahora es claro que tras el proceso de inflamación exacerbado sobreviene un estado de supresión inmune consecuencia de la respuesta homeostática anti-inflamatoria que busca recobrar el equilibrio después de un episodio infeccioso. Sin embargo, en el paciente séptico muchas veces no se alcanza un balance entre estos dos procesos y finalmente sucumbe ante infecciones secundarias debido a la parálisis inmune producto de la acción conjunta de todos los mediadores descritos.

De este modo, la respuesta inmune del hospedero más que la misma infección, determina el desenlace del paciente; y esta respuesta varía entre individuos y aun en el mismo individuo con el transcurso del tiempo. Los estudios que evalúan una única terapia anti-inflamatoria pueden arrojar resultados positivos en aquellos individuos con respuestas pro-inflamatorias predominantes, pero pueden mostrar efectos perjudiciales en aquellos sujetos en los que predomina la respuesta anti-inflamatoria. De hecho, ensayos piloto pequeños, que incluyen grupos de 


\section{Infectología al Día}

pacientes más selectos, muestran resultados alentadores pero que no han podido ser reproducidos en los vastos ensayos de fase III ${ }^{65}$.

El papel que las células con propiedades inmuno-reguladoras descritas previamente pueden desempeñar dentro del proceso séptico es complejo en la medida que su acción pro o anti-inflamatoria depende de los diferentes fenotipos que dichas poblaciones pueden exhibir. El predominio de una respuesta inmunosupresora durante las fases iniciales de la sepsis, estaría asociado con la persistencia del microorganismo patógeno desencadenante del proceso infeccioso. Por el contrario, si la inmuno-regulación predomina en fases tardías, estaría asociada con la parálisis inmunológica característica de un cuadro de sepsis con evolución clínica grave. Mientras no se encuentre un fenotipo inmune explícito que pueda identificarse en todos los pacientes, las investigaciones acerca de la inmunología de la sepsis serán válidas en la medida en que logren explorar y caracterizar los mecanismos comunes de dichas respuestas.

Agradecimientos. Al fondo Sostenibilidad 2009-2011, Universidad de Antioquia por la financiación.

\section{Referencias}

1.- Angus D C, Linde-Zwirble W T, Lidicker J, Clermont G, Carcillo J, Pinsky M R. Epidemiology of severe sepsis in the United States: analysis of incidence, outcome, and associated costs of care. Crit Care Med 2001; 29 (7): 1303-10.

2.- Jaimes F. A literature review of the epidemiology of sepsis in Latin America. Rev Panam Salud Pública 2005; 18 (3): 163-71.

3.- Levy M M, Fink M P, Marshall J C, Abraham E, Angus D, Cook D, et al. $2001 \mathrm{SCCM} / \mathrm{ESICM} /$ ACCP/ATS/SIS International Sepsis Definitions Conference. Crit Care Med 2003; 31 (4): 1250-6.

4.- Bone R C, Balk R A, Cerra F B, Dellinger R P, Fein A M, Knaus W A, et al. Definitions for sepsis and organ failure and guidelines for the use of innovative therapies in sepsis. The ACCP/ SCCM Consensus Conference Committee. American College of Chest Physicians/Society of Critical Care Medicine. Chest 1992; 101: 1644-55.

5.- Hotchkiss R S, Karl I E. The pathophysiology and treatment of sepsis. N Engl J Med 2003; 348 (2): 138-50

6.- Van der Poll T, Opal S M. Host-pathogen interactions in sepsis. Lancet Infect Dis 2008; 8 (1): 32-43.

7.- Gao H, Leaver S K, Burke-Gaffney A, Finney S J. Severe sepsis and toll-like receptors. Semin Immunopathol 2008; 30 (1): 29-40.

8.- Sriskandan S, Altmann D M. The immunology of sepsis. J Pathol 2008; 214 (2): 211-23.

9.- Flaster H, Bernhagen J, Calandra T, Bucala R. The macrophage migration inhibitory factorglucocorticoid dyad: regulation of inflammation and immunity. Mol Endocrinol 2007; 21 (6): 1267-80.

\section{Resumen}

El síndrome de respuesta sistémica consecuencia de una infección, denominado sepsis, constituye una causa significativa de muerte en el mundo. Históricamente se ha aceptado que la muerte por sepsis se debe a un estado de hiperactivación inmunológica, que implica el desarrollo de una vasta respuesta pro-inflamatoria acompañada de alteraciones en el sistema de coagulación. Ahora es claro que además de los sucesos inflamatorios, el curso clínico de la sepsis se caracteriza por el desarrollo de una respuesta anti-inflamatoria que busca contrarrestar la respuesta inicial, y es ésta finalmente en gran parte responsable de la muerte de los pacientes. El propósito de esta revisión es resumir los mecanismos actuales que explican la patogénesis de la sepsis, y específicamente el papel que desempeñan las subpoblaciones celulares con propiedades inmuno-reguladoras durante el curso de la enfermedad. El mejor entendimiento de estos procesos contribuirá a la búsqueda de estrategias terapéuticas más exitosas.
10.- Calandra T, Echtenacher B, Roy D L, Pugin J, Metz C N, Hultner L, et al. Protection from septic shock by neutralization of macrophage migration inhibitory factor. Nat Med 2000; 6 (2): 164-70.

11.- Bozza M, Satoskar A R, Lin G, Lu B, Humbles A A, Gerard C, et al. Targeted disruption of migration inhibitory factor gene reveals its critical role in sepsis. J Exp Med 1999; 189 (2): 341-6.

12.- Andersson U, Wang H, Palmblad K, Aveberger A C, Bloom O, Erlandsson-Harris $\mathrm{H}$, et al. High mobility group 1 protein (HMG-1) stimulates proinflammatory cytokine synthesis in human monocytes. J Exp Med 2000; 192 (4): 565-70.

13.- Bone R C, Grodzin C J, Balk R A. Sepsis: a new hypothesis for pathogenesis of the disease process. Chest 1997; 112 (1): 235-43.

14.- Zeni F, Freeman B, Natanson C. Antiinflammatory therapies to treat sepsis and septic shock: a reassessment. Crit Care Med 1997; 25 (7): 1095-100.

15.- Wang T S, Deng J C. Molecular and cellular aspects of sepsis-induced immunosuppression. J Mol Med 2008; 86 (5): 495-506.

16.- Jonuleit H, Schmitt E, Stassen M, Tuettenberg A, Knop J, Enk A H. Identification and functional characterization of human CD4(+) $\mathrm{CD} 25(+) \mathrm{T}$ cells with regulatory properties isolated from peripheral blood. J Exp Med 2001; 193 (11): 1285-94.

17.- Liu W, Putnam AL, Xu-Yu Z, Szot G L, Lee M R, Zhu S, et al. CD127 expression inversely correlates with FoxP3 and suppressive function of human CD4+ T reg cells. J Exp Med 2006; 203 (7): 1701-11

18.- Campbell D J, Ziegler S F. FOXP3 modifies the phenotypic and functional properties of regulatory T cells. Nat Rev Immunol 2007; 7 (4): 305-10.

19.- von Boehmer H. Mechanisms of suppression by suppressor T cells. Nat Immunol 2005; 6 (4): 338-44.

20.- Belkaid Y, Rouse B T. Natural regulatory T cells in infectious disease. Nat Immunol 2005; 6 (4): 353-60.

21.- Monneret G, Debard A L, Venet F, Bohe J, Hequet O, Bienvenu J, et al. Marked elevation of human circulating $\mathrm{CD} 4+\mathrm{CD} 25+$ regulatory $\mathrm{T}$ cells in sepsis-induced immunoparalysis. Crit Care Med 2003; 31 (7): 2068-71.

22.- Venet F, Pachot A, Debard A L, Bohe J, Bienvenu J, Lepape A, et al. Increased percentage of CD4+CD25+ regulatory T cells during septic shock is due to the decrease of CD4+CD25- lymphocytes. Crit Care Med 2004; 32: 2329-31.

23.- Saito K, Wagatsuma T, Toyama H, Ejima Y, Hoshi K, Shibusawa M, et al. Sepsis is characterized by the increases in porcentages of circulating $\mathrm{CD} 4+\mathrm{CD} 25+$ regulatory $\mathrm{T}$ cells and plasma levels of soluble CD25. J Exp Med 2008; 216: 61-8.

24.- MacConmara M P, Maung A A, Fujimi S, McKenna A M, Delisle A, Lapchak P H, et al. Increased CD4+ CD25+ T regulatory cell activity in trauma patients depresses protective Th1 immunity. Ann Surg 2006; 244 (4): 514-23.

25.- Wisnoski N, Chung C S, Chen Y, Huang X, Ayala A. The contribution of CD4+ CD25+ T-regulatory-cells to immune suppression in sepsis. Shock 2007; 27 (3): 251-7.

26.- Scumpia P O, Delano M J, Kelly K M, O'Malley K A, Efron P A, McAuliffe P F, et al. Increased natural $\mathrm{CD} 4+\mathrm{CD} 25+$ regulatory $\mathrm{T}$ cells and their suppressor activity do not 
contribute to mortality in murine polymicrobial sepsis J Immunol 2006; 177: 7943-9.

27.- Venet F, Chung C S, Kherouf H, Geeraert A, Malcus C, Poitevin F, et al. Increased circulating regulatory $\mathrm{T}$ cells (CD4(+)CD25 (+)CD127 (-)) contribute to lymphocyte anergy in septic shock patients. Intensive Care Medicine 2009; 35 (4): 678-86.

28.- Monneret G, Venet F, Pachot A, Lepape A. Monitoring immune dysfunctions in the septic patient: a new skin for the old ceremony. Mol Med 2008; 14 (1-2): 64-78.

29.- Heath W R, Belz G T, Behrens G M, Smith C M, Forehan S P, Parish I A, et al. Cross presentation, dendritic cell subsets, and the generation of immunity to cellular antigens. Immunol Rev 2004; 199: 9-26.

30.- Sirgo G, Claramonte R, Chanovas M, Esteban F, Forcadell I, Luna J, et al. Dendritic cells in sepsis: an approach to post-infectious immunosuppression. Med Intensiva; 34 (8): 559-66.

31.- Efron P A, Martins A, Minnich D, Tinsley K, Ungaro R, Bahjat F R, et al. Characterization of the systemic loss of dendritic cells in murine lymph nodes during polymicrobial sepsis. J Immunol 2004; 173 (5): 3035-43.

32.- Scumpia P O, McAuliffe P F, O’Malley K A, Ungaro R, Uchida T, Matsumoto T, et al. $\mathrm{CD} 11 \mathrm{c}+$ dendritic cells are required for survival in murine polymicrobial sepsis. J Immunol 2005; 175 (5): 3282-6.

33.- Flohe S B, Agrawal H, Schmitz D, Gertz M, Flohe S, Schade F U. Dendritic cells during polymicrobial sepsis rapidly mature but fail to initiate a protective Th1-type immune response. J Leukoc Biol 2006; 79 (3): 473-81.

34.- Wen H, Dou Y, Hogaboam C M, Kunkel S L. Epigenetic regulation of dendritic cell-derived interleukin-12 facilitates immunosuppression after a severe innate immune response. Blood 2008; 111 (4): 1797-804.

35.- Hotchkiss R S, Tinsley K W, Swanson P E, Grayson M H, Osborne D F, Wagner T H, et al. Depletion of dendritic cells, but not macrophages, in patients with sepsis. J Immunol 2002; 168 (5): 2493-500.

36.- Guisset O, Dilhuydy M S, Thiebaut R, Lefevre J, Camou F, Sarrat A, et al. Decrease in circulating dendritic cells predicts fatal outcome in septic shock. Intensive Care Med 2007; 33 (1): 148-52.

37.- Cooper M A, Fehniger T A, Caligiuri M A. The biology of human natural killer-cell subsets. Trends Immunol 2001; 22 (11): 633-40.

38.- Enoh V T, Lin S H, Lin C Y, Toliver-Kinsky T, Murphey E D, Varma T K, et al. Mice depleted of alphabeta but not gammadelta T cells are resistant to mortality caused by cecal ligation and puncture. Shock 2007; 27 (5): 507-19.

39.- Sherwood E R, Enoh V T, Murphey E D, Lin C Y. Mice depleted of CD8+ T and NK cells are resistant to injury caused by cecal ligation and puncture. Lab Invest 2004; 84 (12): 1655-65.

40.- Goldmann O, Chhatwal G S, Medina E. Contribution of natural killer cells to the pathogenesis of septic shock induced by Streptococcus pyogenes in mice. J Infect Dis 2005; 191 (8): 1280-6.

41.- Diefenbach A, Jamieson A M, Liu S D, Shastri N, Raulet D H. Ligands for the murine NKG2D receptor: expression by tumor cells and activation of NK cells and macrophages. Nat Immunol 2000;1 (2): 119-26.

42.- Wilson M T, Johansson C, Olivares-Villagomez D, Singh A K, Stanic A K, Wang C R, et al. The response of natural killer $\mathrm{T}$ cells to glycolipid antigens is characterized by surface receptor down-modulation and expansion. Proc Natl Acad Sci U S A 2003; 100 (19): 10913-8.

43.- Sidobre S, Naidenko O V, Sim B C, Gascoigne N R, García K C, Kronenberg M. The V alpha 14 NKT cell TCR exhibits high-affinity binding to a glycolipid/CD1d complex. J Immunol 2002; 169 (3): 1340-8.

44.- Smyth M J, Thia K Y, Street S E, Cretney E, Trapani JA, Taniguchi M, et al. Differential tumor surveillance by natural killer (NK) and NKT cells. J Exp Med 2000; 191 (4): 661-8.

45.- van der Vliet H J, von Blomberg B M, Nishi N, Reijm M, Voskuyl A E, van Bodegraven A A, et al. Circulating V(alpha24+) Vbeta11+ NKT cell numbers are decreased in a wide variety of diseases that are characterized by autoreactive tissue damage. Clin Immunol 2001; 100 (21): 44-8.

46.- Godfrey D I, Hammond K J, Poulton L D, Smyth M J, Baxter A G. NKT cells: facts, functions and fallacies. Immunol Today 2000; 21 (11): 573-83.

47.- Gumperz J E, Miyake S, Yamamura T, Brenner M B. Functionally distinct subsets of CD1d-restricted natural killer T cells revealed by CD1d tetramer staining. J Exp Med 2002; 195 (5): 625-36.

48.- Nicol A, Nieda M, Koezuka Y, Porcelli S, Suzuki K, Tadokoro K, et al. Dendritic cells are targets for human invariant Valpha24+ natural killer T-cell cytotoxic activity: an important immune regulatory function. Exp Hematol 2000; 28 (3): 276-82.

49.- Dieli F, Sireci G, Russo D, Taniguchi M, Ivanyi $\mathrm{J}$, Fernández C, et al. Resistance of natural killer T cell-deficient mice to systemic Shwartzman reaction. J Exp Med 2000; 192 (11): 1645-52.

50.- Tsujimoto H, Ono S, Matsumoto A, Kawabata T, Kinoshita M, Majima T, et al. A critical role of $\mathrm{CpG}$ motifs in a murine peritonitis model by their binding to highly expressed toll-like receptor-9 on liver NKT cells. J Hepatol 2006; 45 (6): 836-43.

51.- Stevenson H L, Crossley E C, Thirumalapura N, Walker D H, Ismail N. Regulatory roles of CD1d-restricted NKT cells in the induction of toxic shock-like syndrome in an animal model of fatal ehrlichiosis. Infect Immun 2008; 76 (4): 1434-44.

52.- Rhee R J, Carlton S, Lomas J L, Lane C, Brossay L, Cioffi W G, et al. Inhibition of CD1d activation suppresses septic mortality: a role for NK-T cells in septic immune dysfunction. J Surg Res 2003; 115 (1): 74-81.
53.- Faunce D E, Gamelli R L, Choudhry M A, Kovacs E J. A role for CD1d-restricted NKT cells in injury-associated T cell suppression. J Leukoc Biol 2003; 73 (6): 747-55.

54.- Cipriani B, Borsellino G, Poccia F, Placido R, Tramonti D, Bach S, et al. Activation of $\mathrm{C}$-C beta-chemokines in human peripheral blood gammadelta $\mathrm{T}$ cells by isopentenyl pyrophosphate and regulation by cytokines. Blood 2000; 95 (1): 39-47.

55.- Ferrick D A, Schrenzel M D, Mulvania T, Hsieh B, Ferlin W G, Lepper H. Differential production of interferon-gamma and interleukin-4 in response to Th1- and Th2stimulating pathogens by gamma delta $\mathrm{T}$ cells in vivo. Nature 1995; 373 (6511): 255-7.

56.- Girardi M, Lewis J, Glusac E, Filler R B, Geng L, Hayday A C, et al. Resident skin-specific gammadelta $\mathrm{T}$ cells provide local, nonredundant regulation of cutaneous inflammation. J Exp Med 2002; 195 (7): 855-67.

57.- Mukasa A, Yoshida H, Kobayashi N, Matsuzaki G, Nomoto K. Gamma delta T cells in infection-induced and autoimmune-induced testicular inflammation. Immunology 1998; 95 (3): 395-401.

58.- Van Damme N, De Keyser F, Demetter P, Baeten D, Mielants H, Verbruggen G, et al. The proportion of Th1 cells, which prevail in gut mucosa, is decreased in inflammatory bowel syndrome. Clin Exp Immunol 2001; 125 (3): 383-90.

59.- Girardi M, Sherling M A, Filler R B, Shires J, Theodoridis E, Hayday AC, et al. Antiinflammatory effects in the skin of thymosinbeta4 splice-variants. Immunology 2003; 109 (1): 1-7.

60.- Moore T A, Moore B B, Newstead M W, Standiford T J. Gamma delta-T cells are critical for survival and early proinflammatory cytokine gene expression during murine Klebsiella pneumonia. J Immunol 2000; 165 (5): 2643-50.

61.- Chung C S, Watkins L, Funches A, LomasNeira J, Cioffi W G, Ayala A. Deficiency of gammadelta $\mathrm{T}$ lymphocytes contributes to mortality and immunosuppression in sepsis. Am J Physiol Regul Integr Comp Physiol 2006; 291 (5): R1338-43.

62.- O’Brien R L, Yin X, Huber S A, Ikuta K, Born W K. Depletion of a gamma delta $T$ cell subset can increase host resistance to a bacterial infection. J Immunol 2000; 165 (11): 6472-9.

63.- Venet F, Bohe J, Debard AL, Bienvenu J, Lepape A, Monneret G. Both percentage of gammadelta T lymphocytes and CD3 expression are reduced during septic shock. Crit Care Med 2005; 33 (12): 2836-40.

64.- Matsushima A, Ogura H, Fujita K, Koh T, Tanaka H, Sumi Y, et al. Early activation of gammadelta $\mathrm{T}$ lymphocytes in patients with severe systemic inflammatory response syndrome. Shock 2004; 22 (1) :11-5.

65.- Vincent J L, Sun Q, Dubois M J. Clinical trials of immunomodulatory therapies in severe sepsis and septic shock. Clin Infect Dis 2002; 34 (8): 1084-93. 